\title{
24-Hour Ambulatory Blood Pressure Monitoring in SWEDDs Patients With Parkinsonism
}

\author{
Seok-Jae Kang, Jin Young Ahn, Joong-Seok Kim, Jin Whan Cho, Ji Young Kim, \\ Yun Young Choi, Hee-Tae Kim
}

\begin{abstract}
Background: Patients diagnosed with Parkinson's disease (PD) on clinics who subsequently turn out to have normal dopamine transporter images have been referred to as scans without evidence of dopaminergic deficits (SWEDDs) patients. Cardiovascular autonomic dysfunction has frequently been reported in PD. In this study, we determined the similarities and differences in cardiac autonomic dysfunction between SWEDDs and PD patients. This study investigated whether 24-hour ambulatory blood pressure monitoring (24-hour ABPM) can help identify possible cases with SWEDDs. Methods: We enrolled 28 SWEDDs patients, 46 patients with PD, and 30 healthy controls. To evaluate cardiac autonomic function, 24-hour ABPM was performed on all subjects. Cardiac metaiodobenzylguanidine (MIBG) scintigraphy was performed on the SWEDDs and PD subjects. Results: The percentage nocturnal decline in blood pressure differed significantly among SWEDDs patients, PD patients, and controls $(\mathrm{p}<0.05)$. In addition to the abnormal nocturnal BP, regulation (nondipping and reverse dipping) was significantly higher in SWEDDs and PD subjects than in the control subjects $(\mathrm{p}<0.05)$. There was no significant correlation between the \% nocturnal blood pressure reduction and parameters of cardiac MIBG uptake ratio. However, orthostatic hypotension was significant correlated with the nocturnal blood pressure dip (\%), nocturnal blood pressure patterns, and the cardiac MIBG uptake ratio (early and late) in combined SWEDDs and PD subjects. Conclusions: Pathologic nocturnal blood pressure regulation and nocturnal hypertension, known characteristics of PD, are also present in SWEDDs. Moreover, cardiac sympathetic denervation should not be attributed to cardiac autonomic dysfunction in SWEDDs patients. As with PD patients, the SWEDDs patients studied here tended to have cardiac autonomic dysfunction.
\end{abstract}

RÉSUMÉ: Surveillance de $\mathbf{2 4}$ heures de la tension artérielle ambulatoire chez les patients présentant du parkinsonisme sans évidence de déficit dopaminergique. Contexte : Les patients chez qui un diagnostic de maladie de Parkinson (MP) a été posé basé sur la présentation clinique et chez qui éventuellement l'imagerie montre une activité normale du transporteur de la dopamine sont connus comme étant des patients avec scan sans évidence de déficit dopaminergique (scans without evidence of dopaminergic deficits - SWEDDs patients). Une dystonie neurovégétative cardiovasculaire a souvent été rapportée dans la MP. Dans cette étude, nous identifions les similitudes et les différences de la dystonie neuro-végétative cardiaque entre les patients atteints de SWEDD et les patients atteints de MP. Nous avons examiné si l'enregistrement de la tension artérielle ambulatoire de 24 heures (ETAA $24 \mathrm{~h}$ ) pouvait aider à identifier les cas possibles de SWEDD. Méthode : Nous avons recruté 28 patients atteints de SWEDD, 46 patients atteints de MP et 30 sujets témoins en bonne santé. Un ETAA 24 $\mathrm{h}$ a été effectué chez tous les sujets afin d'évaluer la fonction neurovégétative cardiaque. Une scintigraphie cardiaque à la métaiodobenzylguanidine (MIBG) a été effectuée chez les sujets atteints de SWEDD et de MP. Résultats : Le pourcentage de diminution nocturne de la tension artérielle était significativement différent chez les patients atteints de SWEDD, les patients atteints de MP et les sujets témoins ( $\mathrm{p}<0,05)$. En plus de la TA nocturne anormale, la régulation (absence de diminution et diminution inversée) de la TA était significativement plus élevée chez les sujets atteints de SWEDD et de MP que chez les sujets témoins (p < 0,05). Il n'existait pas de corrélation significative entre le \% de réduction de la tension artérielle nocturne et les paramètres du ratio de captation cardiaque de MIBG. Cependant, l'hypotension orthostatique était corrélée significativement à la baisse (\%) de la tension artérielle nocturne, au profil de la tension artérielle nocturne et au ratio de captation cardiaque de MIBG (précoce et tardif) chez les patients atteints de SWEED et de MP. Conclusions : La régulation nocturne pathologique de la tension artérielle et l'hypertension nocturne, des caractéristiques bien connues de la MP, sont également présentes chez les patients atteints de SWEDD. De plus, la dénervation sympathique cardiaque ne devrait pas être attribuée à une dystonie neurovégétative cardiaque chez les patients atteints de SWEDD. Comme chez les patients atteints de MP, les patients atteints de SWEDD que nous avons étudiés avaient tendance à présenter une dystonie neurovégétative cardiaque.

Keywords: 24-hour ambulatory blood pressure monitoring (ABPM), SWEDDs, non-dipping, nocturnal hypotension, orthostatic hypotension, cardiac MIBG uptake

doi:10.1017/cjn.2015.385

Can J Neurol Sci. 2016; 43: 390-397

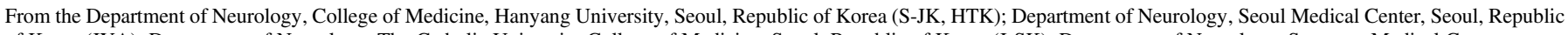
of Korea (JYA); Department of Neurology, The Catholic University College of Medicine, Seoul, Republic of Korea (J-SK); Department of Neurology, Samsung Medical Center,

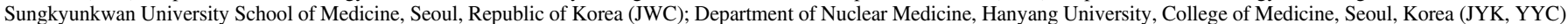
Received January 29, 2015. Final Revisions Submitted July 27, 2015

Correspondence to: Hee Tae Kim, Department of Neurology, College of Medicine, Hanyang University, 222 wansimni 2-dong, Seongdong-gu, Seoul, 133-792, Republic of Korea.

Email: kimht@hanyang.ac.kr 


\section{INTRODUCTION}

The concept of scans without evidence of dopaminergic deficits (SWEDDs) originates from the clinical trial literature for Parkinson's disease (PD), in which dopamine transporter images were made to monitor disease progression; these revealed that normal scans obtained in a substantial proportion of clinically diagnosed cases of PD (4\%-15\%). These patients were therefore designated SWEDDs patients. ${ }^{1-3}$ Some researchers have suggested that SWEDDs patients comprise a spectrum of diseases (idiopathic PD, essential tremor, dystonic tremor, and other parkinsonisms). ${ }^{2-4}$

$\mathrm{PD}$ is characterized by multisystem degeneration. ${ }^{5,6}$ Traditionally, it is considered a motor disorder, but nonmotor symptoms have been established in the past decade. The usual nonmotor symptoms include cognitive dysfunctions, psychiatric problems, autonomic failures, and sleep difficulties. ${ }^{7}$ The nonmotor symptoms are important to patients and have been found to have a severe effect on quality of life. Cardiovascular autonomic dysfunction has frequently been reported in PD. One of the clinically important non-motor features of PD is altered blood pressure (BP) regulation. Loss of the circadian rhythm of BP is an early sign of dysautonomia in PD patients with orthostatic hypotension. ${ }^{8}$ A variety of circadian abnormalities that can influence hemodynamic changes are found in patients with PD. In particular, fluctuating $\mathrm{BP}$, decreased heart rate variability, nocturnal BP nondipping, and nocturnal hypertension are common. $^{9}$

Loss of the nocturnal BP fall was previously reported in various extrapyramidal syndromes (especially in early PD, multiple system atrophy, and progressive supranuclear palsy patients), ${ }^{10}$ and loss of or decreased nocturnal BP fall (nondipper) can be a marker of autonomic dysfunction. ${ }^{5}$ High nocturnal BP is associated with increased cardiovascular mortality; therefore, early detection is important. ${ }^{11} \mathrm{BP}$ variability is influenced by sympathetic factors. In addition, there is a significant correlation between systemic BP profile and cardiac ${ }^{123}$ I-metaiodobenzylguanidine (MIBG) uptake in patients with PD. ${ }^{12}$ Therefore, we investigated this profile in SWEDDs patients.

In this study, we determined the similarities and differences in cardiac autonomic dysfunction in SWEDDs versus PD patients. In addition, to confirm whether a relationship exists between abnormal findings for cardiac MIBG uptake and quantitative BP profile data, we performed both examinations in the SWEDDs and PD patients. Additionally, 24-hour ambulatory BP (ABPM) profiles and cardiac MIBG uptake differences were compared in patients with orthostatic hypotension and without orthostatic hypotension.

\section{Materials ANd Methods}

\section{Subjects}

Subjects who had PD were recruited from Hanyang University Hospital from January 2010 to May 2013. The SWEDDs patients were defined by the following criteria: adult onset (age $>40$ years) of parkinsonian symptoms, including asymmetric resting tremor or akinetic rigidity, previous diagnosis of PD by a specialist, and normal dopamine transporter imaging ( ${ }^{123}$ I-fluoropropyl2-beta-carbomethoxy-3-beta[4-iodophenyl] nortropane positron emission tomography [FP-CIT PET]). The dopamine transporter scans of the patients were inspected by nuclear medicine clinicians who were not aware of the clinical information. The patients in the PD group fulfilled UK brain bank PD criteria ${ }^{13}$ and had abnormal FP-CIT PET findings. Patients with possible secondary causes of their parkinsonism were excluded. None of the patients were administered dopaminergic drugs until the tests were completed. We excluded patients with relevant cardiac problems, medical disorders, history of neuropathy, or current medication use (central nervous system stimulants, monoamine oxidase inhibitors, opioids, selective serotonin reuptake inhibitors, and sympathomimetics), which could have influenced the FP-CIT PET or cardiac MIBG scintigraphy. All individuals in the control group were in good health as established by chart review.

Basic patient demographic and clinical data were obtained for each patient. Disease severity was evaluated according to the unified PD rating scale (UPDRS) score and Hoehn and Yahr stage. Orthostatic hypotension was measured in the SWEDDs and PD patients. According to the American Autonomic Society, the definition of orthostatic hypotension is a constant decrease of the systolic blood pressure to $\geq 20 \mathrm{mmHg}$ and diastolic blood pressure to $\geq 10 \mathrm{mmHg}$ within 3 minutes of a change in standing position. ${ }^{14}$

\section{4-Hour ABPM}

All patients underwent 24-hour ABPM using a noninvasive portable recorder (TM-2430; A\&D Medical, Saitama, Japan). The subjects were free to move during the recording. BP was assessed in the upper extremities every 15 minutes during the day and every 30 minutes during the night.

The following parameters were calculated from the raw data: 24-hour mean systolic BP (SBP)/diastolic BP (DBP)/mean arterial BP (MABP), waking SBP/DBP/MABP, sleeping SBP/DBP/ MABP, 24-hour heart rate (HR), daytime HR, nighttime HR, and nocturnal BP fall (dipper, nondipper, reverse dipper). The individual parameters were defined as follows: nighttime BP was defined as the average of the BP at the onset of sleep and awakening based on the activity sheet. According to the American Heart Association Council on High Blood Pressure Research, nocturnal hypertension is defined as nocturnal BP $>125 / 75$ and daytime hypertension is defined as daytime BP $>140 / 90 .{ }^{15}$ Mean daytime and nighttime SBP and DBP were calculated, and the nocturnal BP dip (\%) was calculated as follows: (daytime SBP nighttime SBP)/daytime $\mathrm{SBP} \times 100 .{ }^{15}$ Subjects were divided into three subgroups according to the magnitude of the fall in BP, dippers (those who showed ordinary nocturnal falls $[10 \% \leq$ nocturnal BP reductions]); nondippers (those whose BP did not fall by the usual amount $[0 \% \leq$ nocturnal $\mathrm{BP}$ fall $<10 \%]$ ); and reverse dippers (those whose BP increased during the night).

\section{MIBG Scans}

Cardiac MIBG scans were performed 20 minutes and 3 hours after intravenous injection of an average of $111 \mathrm{MBq}(3 \mathrm{mCi})$ 123I-MIBG using a dual-head gamma camera (ECAM, Siemens Medical Systems, Chicago, IL, USA). The cardiac and mediastinal regions of interest were drawn for semiquantification of the 123I-MIBG uptake. Heart-to-mediastinum (H/M) uptake ratios and washout rates (WRs) were calculated using the following formulas: $\mathrm{H} / \mathrm{M}$ ratio $=$ mean count of heart uptake at 20 minutes/mean count of mediastinum uptake at 3 hours; WR $=$ [mean count of heart 
uptake at 20 minutes (mean count of heart uptake at 3 hours)/mean count in early scan $\times 100$ ].

\section{FP-CIT PET/Computed Tomography}

FP-CIT PET/computed tomography (CT) was conducted in all SWEDDs and PD patients. The PET/CT scans were performed 2 hours after an intravenous injection of an average of $185 \mathrm{MBq}$ $(5 \mathrm{mCi})$ FP-CIT. All subjects underwent PET/CT imaging in a Biograph TruePoint 16 scanner (Siemens Medical Systems, Hoffman Estates, IL, USA). The emission PET data were acquired for 10 minutes, and the CT data were used for the attenuation correction. The dopamine transporter binding state was evaluated through visual analysis and semiquantitative analysis of the FP-CIT PET/CT. Semiquantitative analyses were performed using the specific to nonspecific binding ratio and the asymmetric index (AI). The regions of interest were identified and drawn on both caudate nuclei, both putamen, and the occipital cortex. Standardized uptake values were taken from each area, and three adjacent slices where the striatum was best observed were used for the analysis. The specific to nonspecific binding ratio was calculated using the following formula: (average standardized uptake value of striatum - average standardized uptake value of occipital cortex)/average standardized uptake value of occipital cortex. The AI was calculated according to (better uptake - worse uptake)/better uptake.

\section{Statistical Analysis}

The data were analyzed using SPSS 21.0. Analysis of variance and Pearson's chi-squared tests were used to compare the 24-hour ABPM profiles, H/M ratios, WRs, and clinical features of the three groups. Student's t test was used to compare 24-hour ABPM profiles, cardiac MIBG uptake, and clinical features between patients with and without orthostatic hypotension. All $\mathrm{p}$ values of $<0.05$ were considered statistically significant. Results are presented as mean values ( \pm standard deviations).

\section{RESULTS}

A comparison of the baseline demographic and clinical data between the PD patients, SWEDDs patients, and control group is shown in Table 1. No significant differences were observed with respect to age, sex, disease duration, or UPDRS III. However, disease severity (Hoehn and Yahr stage) was higher in the PD group $(2.35 \pm 1.02)$ than in the SWEDDs group $(1.89 \pm 0.74)$.
In addition, orthostatic hypotension was more frequent in the PD group $(37 \%)$ than in the SWEDDs group (14.3\%) (Table 1). Table 2 presents the detailed clinical features of the 28 SWEDDs patients. All had bradykinesia with other parkinsonian symptoms, but three had not been using dopaminergic drugs because of negative responses to levodopa.

Daytime mean DBP and MABP were significantly lower in the SWEDDs patients than in controls $(\mathrm{p}<0.05)$. Nocturnal hypertension was more frequent in the SWEDDs and PD groups than in the control group $(\mathrm{p}<0.05)$. The percentage nocturnal BP dips were significantly different among SWEDDs patients, PD patients, and control subjects $(\mathrm{p}<0.05)$. Nocturnal BP patterns but did not differ significantly between the SWEDDs and PD groups, but they did differ between the two patient groups and the controls $(\mathrm{p}<0.05)$ (Table 3) (Figure 1).

A comparison of cardiac MIBG uptake in the SWEDDs and $\mathrm{PD}$ groups revealed that the early $\mathrm{H} / \mathrm{M}$ ratio was higher in the SWEDDs $(2.53 \pm 0.60)$ patients than in the PD patients $(2.00 \pm 0.47)(\mathrm{p}<0.05)$. The late $\mathrm{H} / \mathrm{M}$ ratio was also higher in the SWEDDs $(2.80 \pm 0.90)$ than the PD patients $(1.94 \pm 0.66)$ $(\mathrm{p}<0.05)$. Finally, washout rates $(\%)$ were higher in the PD $(23.42 \pm 11.15)$ than in the SWEDDs patients $(14.85 \pm 12.20)$ $(\mathrm{p}<0.05)$.

The results of comparisons between the combined SWEDDs and PD patients with and without orthostatic hypotension are shown in Table 4. There were significant differences in diurnal hypertension, nocturnal BP dip (\%), nocturnal BP patterns (Figure 2), and cardiac MIBG uptake ratio (early and late) (Table 4).

When comparing FP-CIT PET/CT parameters, significant differences were observed in the SNBRs for both the striatum and in the AIs for the caudate and putamen between the two groups ( $\mathrm{p}<0.001$ in all areas, $\mathrm{p}<0.005$ in asymmetric index, caudate). Table 5 shows the mean SNBRs for the caudate and putamen and the AI indices for the caudate and putamen in each group.

We also performed a correlation analysis, but found no correlations between the absence of a nocturnal blood pressure dip and disease duration, age, or MIBG uptake profiles.

\section{Discussion}

In this study, we demonstrated for the first time that 24-hour ABPM has an altered nocturnal 24-hour BP profile in most SWEDDs patients. Therefore, ABPM could even be useful for detecting autonomic dysfunction in SWEDDs patients. In addition,

Table 1: Dermographics of the patients with SWEDDs and PD at baseline and of the control subjects

\begin{tabular}{|c|c|c|c|c|}
\hline & SWEDDs $(n=28)$ & PD $(n=46)$ & Control $(n=30)$ & p value \\
\hline Sex: female/male & $10 / 18$ & $19 / 27$ & $15 / 15$ & $0.544 *$ \\
\hline Age & $70.0 \pm 8.4$ & $66.9 \pm 9.1$ & $66.3 \pm 9.3$ & $0.241 *$ \\
\hline Disease duration (months) & $33.3 \pm 38.9$ & $33.5 \pm 36.8$ & NA & $0.987^{\dagger}$ \\
\hline Hoehn and Yahr staging & $1.8 \pm 0.7$ & $2.3 \pm 1.0$ & NA & $0.043^{\dagger}$ \\
\hline UPDRS part III & $22.5 \pm 15.2$ & $27.1 \pm 15.4$ & NA & $0.208^{\dagger}$ \\
\hline Orthostatic hypotension, n (\%) & $4(14.3 \%)$ & $17(37 \%)$ & $0(0 \%)$ & $0.036^{\ddagger}$ \\
\hline
\end{tabular}

Data are presented as mean \pm standard deviation or number $(\%)$.

$\mathrm{NS}=$ not significant; $\mathrm{NA}=$ not applicable.

*Analysis of variance, ${ }^{\dagger}$ Student $t$ test, and ${ }^{*}$ Pearson $\chi^{2}$ test were used to determine $\mathrm{p}$ values. 
Table 2: Clinical features in 28 patients with SWEDDs

\begin{tabular}{|c|c|c|c|c|c|c|c|c|c|}
\hline No & Sex & Age & $\begin{array}{c}\text { Durations } \\
\text { (years) }\end{array}$ & $\begin{array}{c}\text { Used } \\
\text { dopaminergic } \\
\text { drugs? }\end{array}$ & $\begin{array}{c}\text { Types of } \\
\text { dopaminergic } \\
\text { drugs }\end{array}$ & $\begin{array}{l}\text { LED of dopamine } \\
\text { agonists (last } \\
\text { visit) }\end{array}$ & $\begin{array}{l}\text { Total LED } \\
\text { (last visit) }\end{array}$ & $\begin{array}{l}\text { L-dopa } \\
\text { response }\end{array}$ & Parkinsonian signs \\
\hline 1 & $\mathrm{~F}$ & 72 & 0.5 & Yes & Le, $\operatorname{Pr}$ & 25 & 175 & Positive & TR, TP, B, R, S \\
\hline 2 & $\mathrm{M}$ & 71 & 3.6 & Yes & Le, En, $\operatorname{Pr}$ & 75 & 275 & Positive & $\mathrm{TR}, \mathrm{TP}, \mathrm{B}, \mathrm{R}$ \\
\hline 3 & $\mathrm{~F}$ & 71 & 2 & Yes & Le, $\operatorname{Pr}$ & 75 & 325 & Positive & $\mathrm{TR}, \mathrm{B}, \mathrm{R}, \mathrm{S}$ \\
\hline 4 & $F$ & 77 & 0.3 & Yes & Le, Ro & 40 & 790 & Positive & $\mathrm{TR}, \mathrm{B}, \mathrm{R}, \mathrm{S}, \mathrm{A}$ \\
\hline 5 & $\mathrm{~F}$ & 79 & 7 & Yes & $\mathrm{Am}$ & & 200 & Positive & TR, TP, B, R, S, A \\
\hline 6 & $\mathrm{M}$ & 72 & 1 & Yes & Le, $\operatorname{Pr}$ & 150 & 900 & Positive & TR, TP, B, R, S, A \\
\hline 7 & $\mathrm{~F}$ & 51 & 0.3 & No & & & & Negative & TR, TP, B, R \\
\hline 8 & $F$ & 76 & 1 & Yes & $\mathrm{Am}, \mathrm{Pr}$ & 25 & 125 & Positive & $\mathrm{TR}, \mathrm{B}, \mathrm{R}$ \\
\hline 9 & $F$ & 66 & 0.5 & Yes & $\mathrm{Am}, \mathrm{Le}, \mathrm{Pr}$ & 25 & 275 & Positive & $\mathrm{TR}, \mathrm{B}, \mathrm{R}$ \\
\hline 10 & $\mathrm{~F}$ & 78 & 6 & Yes & Le, En, $\operatorname{Pr}$ & 150 & 950 & Positive & TR, TP, B, R \\
\hline 11 & $\mathrm{M}$ & 72 & 5 & Yes & Am, Le, Ro & 80 & 380 & Positive & $\mathrm{TP}, \mathrm{B}, \mathrm{R}, \mathrm{S}, \mathrm{A}$ \\
\hline 12 & $F$ & 74 & 2 & Yes & $\mathrm{Am}, \mathrm{Le}$ & & 250 & Positive & $\mathrm{TR}, \mathrm{TP}, \mathrm{B}, \mathrm{R}, \mathrm{S}, \mathrm{A}$ \\
\hline 13 & $\mathrm{~F}$ & 65 & 3 & Yes & $\mathrm{Am}, \mathrm{Se}$ & & 75 & Positive & $\mathrm{TR}, \mathrm{R}, \mathrm{B}$ \\
\hline 14 & $F$ & 68 & 2 & Yes & $\operatorname{Pr}$ & 125 & 125 & Positive & $\mathrm{TR}, \mathrm{B}, \mathrm{R}$ \\
\hline 15 & $\mathrm{~F}$ & 69 & 0.3 & Yes & $\mathrm{Se}$ & & 25 & Positive & $\mathrm{B}, \mathrm{R}, \mathrm{A}$ \\
\hline 16 & $F$ & 53 & 2 & Yes & $\mathrm{Am}, \mathrm{Pr}$ & 75 & 275 & Positive & $\mathrm{TP}, \mathrm{B}, \mathrm{R}, \mathrm{A}$ \\
\hline 17 & $\mathrm{~F}$ & 75 & 2 & Yes & $\mathrm{Le}$ & & 150 & Positive & $\mathrm{TR}, \mathrm{B}, \mathrm{R}, \mathrm{A}$ \\
\hline 18 & $F$ & 77 & 4 & Yes & Am, Le, Ro & 40 & 740 & Positive & $\mathrm{TR}, \mathrm{B}, \mathrm{R}, \mathrm{S}, \mathrm{A}$ \\
\hline 19 & $\mathrm{M}$ & 74 & 0.8 & Yes & Am, Le, $\operatorname{Pr}$ & 25 & 525 & Positive & $\mathrm{TR}, \mathrm{B}, \mathrm{R}$ \\
\hline 20 & $\mathrm{~F}$ & 64 & 3 & No & & & & Negative & TR, TP, B, R \\
\hline 21 & $\mathrm{~F}$ & 75 & 2 & Yes & Am, Le, Pr & 75 & 425 & Positive & $\mathrm{TR}, \mathrm{B}, \mathrm{R}, \mathrm{A}$ \\
\hline 22 & $\mathrm{~F}$ & 75 & 0.3 & Yes & $\mathrm{Am}, \mathrm{Pr}$ & 100 & 300 & Positive & TR, TP, B, R \\
\hline 23 & $\mathrm{M}$ & 46 & 5 & No & & & 300 & Negative & $\mathrm{B}, \mathrm{R}$ \\
\hline 24 & $\mathrm{M}$ & 76 & 0.3 & Yes & $\mathrm{Am}, \mathrm{Le}$ & & & Positive & $\mathrm{TP}, \mathrm{B}, \mathrm{R}$ \\
\hline 25 & $\mathrm{M}$ & 73 & 0.3 & Yes & Am, Le, En & & 733 & Positive & $\mathrm{TP}, \mathrm{B}, \mathrm{R}$ \\
\hline 26 & $\mathrm{M}$ & 72 & 0.5 & Yes & Le, $\operatorname{Ro}, \operatorname{Pr}$ & 65 & 815 & Positive & $\mathrm{TP}, \mathrm{B}, \mathrm{R}$ \\
\hline 27 & $\mathrm{M}$ & 79 & 1 & Yes & Am, Le, Pr & 200 & 700 & Positive & $\mathrm{TR}, \mathrm{TP}, \mathrm{B}, \mathrm{R}, \mathrm{A}$ \\
\hline 28 & $\mathrm{M}$ & 61 & 2.5 & Yes & $\mathrm{Am}, \mathrm{Pr}$ & 187.5 & 287.5 & Positive & TR, TP, B, R, A \\
\hline
\end{tabular}

$\mathrm{A}=$ axial involvement; $\mathrm{Am}=$ amantadine; $\mathrm{B}=$ bradykinesia; $\mathrm{En}=$ entacapone; Le = levodopa; $\mathrm{LED}=$ levodopa equivalent dose; $\mathrm{Pr}=$ pramipexole; $\mathrm{R}=$ rigidity; $\mathrm{Ro}=$ ropinirole; $\mathrm{S}=$ slowness; $\mathrm{Se}=$ selegiline; $\mathrm{TP}=$ postural tremor; $\mathrm{TR}=$ resting tremor.

similar patterns of cardiovascular autonomic dysfunction were seen in SWEDDs and PD patients.

Studies of nonmotor manifestations have indicated that olfactory dysfunction and cardiac sympathetic denervation could differ between SWEDDs and PD patients. ${ }^{16,17}$ We also observed differences in cardiac sympathetic denervation between SWEDDs and PD patients as in previous reports. This finding may help to differentiate patients with SWEDDs from patients with PD. However, autonomic dysfunction, which is defined by 24-hour ABPM profiles, was observed in both the SWEDDs group and the PD group. As mentioned previously, there is a spectrum of diseases in SWEDDs patients. The difference in nonmotor symptoms between SWEDDs and PD patients might also reflect a different pathophysiology of the two groups. However, we observed similar 24-hour ABPM parameters (nocturnal hypertension, nondipping patterns) in the two groups, suggesting that they have a similar pathophysiology. A recent study suggested that most
SWEDDs cases are the result of the misdiagnosis of dystonic tremor patients; ${ }^{2}$ another study showed that most patients presenting as SWEDDs were rediagnosed with dystonic tremor after long-term follow-up. However, recent studies using longitudinal follow-up data for patients initially diagnosed as SWEDDs patients found that they were rediagnosed to PD, atypical parkinsonism, essential tremor, dystonic tremor, and others., We found that autonomic dysfunction, especially circadian rhythm imbalance (nondipping, nocturnal hypertension), may be a characteristic of SWEDDs patients. Nondipping can be found in various extrapyramidal syndromes (PD, MSA, PSP, CBD). ${ }^{10}$ There is one report that nondipping is correlated with the presence of subcortical ischemic lesions and cognitive impairment. ${ }^{18}$ In the same way, SWEDDs patients may suffer from mild to moderate subcortical vascular parkinsonism. These observations suggest that SWEDDs patients include not only dystonic tremor, but also PD and other Parkinson-plus syndromes. 
Table 3: Summary of the main variables in the ambulatory recording of blood pressure

\begin{tabular}{|c|c|c|c|c|c|}
\hline & SWEDDs $(\mathrm{n}=\mathbf{2 8})$ & $P D(n=46)$ & Control $(n=30)$ & p value* & Post hoc comparison \\
\hline \multicolumn{6}{|l|}{ 24-h ABPM } \\
\hline Daytime mean SBP $(\mathrm{mmHg})$ & $124.6 \pm 11.5$ & $127.3 \pm 12.9$ & $131.3 \pm 9.3$ & 0.091 & SWEDDs $=\mathrm{PD}=$ control \\
\hline Daytime mean DBP $(\mathrm{mmHg})$ & $74.3 \pm 6.6$ & $78.2 \pm 7.6$ & $80.4 \pm 7.3$ & 0.009 & SWEDDs $<$ control \\
\hline Daytime MABP (mmHg) & $91.1 \pm 7.5$ & $94.6 \pm 8.7$ & $97.3 \pm 7.2$ & 0.012 & SWEDDs $<$ control \\
\hline Daytime mean HR (n/min) & $74.4 \pm 8.2$ & $74.8 \pm 9.2$ & $72.5 \pm 7.1$ & 0.493 & SWEDDs $=\mathrm{PD}=$ control \\
\hline Nocturnal mean SBP $(\mathrm{mmHg})$ & $118.9 \pm 11.8$ & $122.7 \pm 19.7$ & $116.3 \pm 10.4$ & 0.199 & SWEDDs $=\mathrm{PD}=$ Control \\
\hline Nocturnal mean DBP (mmHg) & $71.0 \pm 7.2$ & $74.2 \pm 12.3$ & $69.1 \pm 6.0$ & 0.069 & SWEDDs $=\mathrm{PD}=$ control \\
\hline Nocturnal MABP $(\mathrm{mmHg})$ & $86.9 \pm 8.0$ & $90.4 \pm 14.1$ & $84.8 \pm 6.7$ & 0.088 & SWEDDs $=\mathrm{PD}=$ control \\
\hline Nocturnal mean HR (n/min) & $67.3 \pm 10.5$ & $66.1 \pm 9.3$ & $63.3 \pm 7.8$ & 0.231 & SWEDDs $=\mathrm{PD}=$ control \\
\hline 24-h mean SBP (mmHg) & $122.6 \pm 10.9$ & $126.1 \pm 14.0$ & $126.9 \pm 7.6$ & 0.328 & SWEDDs $=\mathrm{PD}=$ control \\
\hline 24-h mean DBP (mmHg) & $74.8 \pm 9.5$ & $77.5 \pm 8.7$ & $77.0 \pm 5.4$ & 0.378 & SWEDDs $=\mathrm{PD}=$ control \\
\hline 24-h MABP (mmHg) & $90.7 \pm 8.7$ & $93.7 \pm 9.8$ & $93.6 \pm 5.3$ & 0.298 & SWEDDs $=\mathrm{PD}=$ control \\
\hline 24-h mean HR (n/min) & $73.2 \pm 11.6$ & $72.6 \pm 9.0$ & $69.6 \pm 7.1$ & 0.271 & SWEDDs $=\mathrm{PD}=$ control \\
\hline Diurnal hypertension, $\mathrm{n}(\%)$ & $4(14.3 \%)$ & $5(10.9 \%)$ & $6(20 \%)$ & $0.549 \dagger$ & \\
\hline Nocturnal hypertension, n (\%) & $14(50 \%)$ & $27(58.7 \%)$ & $9(30 \%)$ & $0.042 \dagger$ & \\
\hline Nocturnal BP dip (\%) & $4.3 \pm 6.9$ & $3.7 \pm 10.2$ & $11.2 \pm 8.7$ & 0.001 & SWEDDs $=$ PD $<$ control \\
\hline Nocturnal BP profile & & & & $0.001 \dagger$ & \\
\hline Dipping, n (\%) & $5(17.9)$ & $13(28.3)$ & $20(66.7)$ & & \\
\hline Nondipping, n (\%) & $18(64.3)$ & $20(43.5)$ & $8(26.7)$ & & \\
\hline Reverse dipping, $\mathrm{n}(\%)$ & $5(17.9)$ & $13(28.3)$ & $2(6.7)$ & & \\
\hline Nocturnal pulse decrease & $5.46 \pm 6.24$ & $9.83 \pm 9.92$ & $9.23 \pm 6.09$ & 0.070 & SWEDDs $=\mathrm{PD}=$ control \\
\hline
\end{tabular}

Data are presented as mean \pm standard deviation or number $(\%)$.

*ANOVA test were used to determine $\mathrm{p}$ values with Bonferroni post hoc paired comparison tests.

$\dagger$ Pearson $\chi^{2}$ test.

The causes of nondipping and nocturnal hypertension are not understood. However, autonomic dysfunction is almost always associated with a nondipping BP profile and sometimes even with

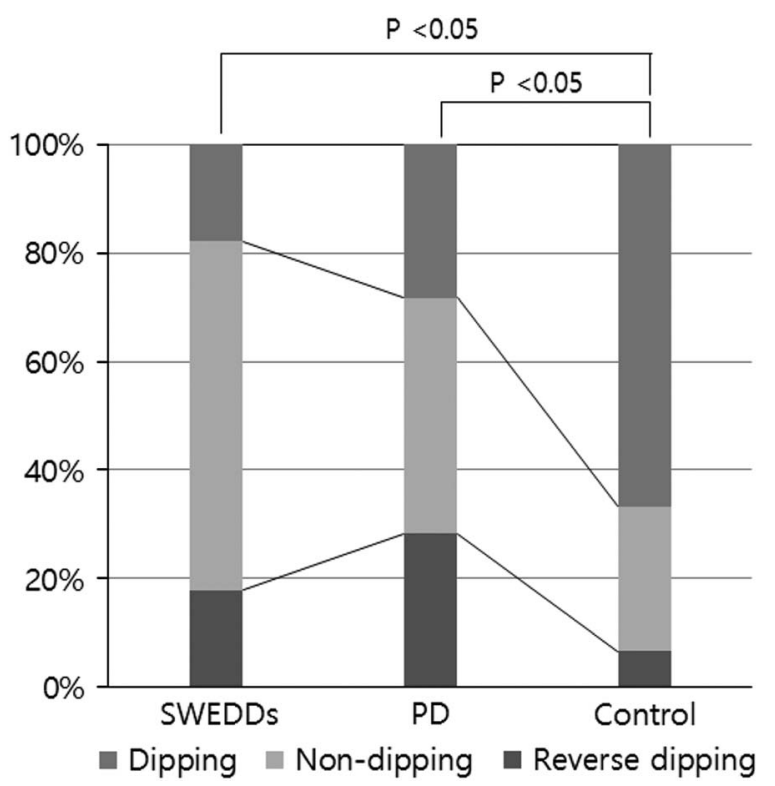

Figure 1: 24-hour blood pressure circadian patterns in SWEDDs, PD, and control. nocturnal hypertension. ${ }^{19,20}$ Daytime inactivity and poor sleep quality may explain the nondipping phenomenon, but nondipping is also related to a number of clinical conditions that usually have no influence on daytime activity and/or sleep quality. ${ }^{19}$ In parkinsonian syndromes, orthostatic hypotension develops as a synergistic effect of cardiovascular noradrenergic denervation and

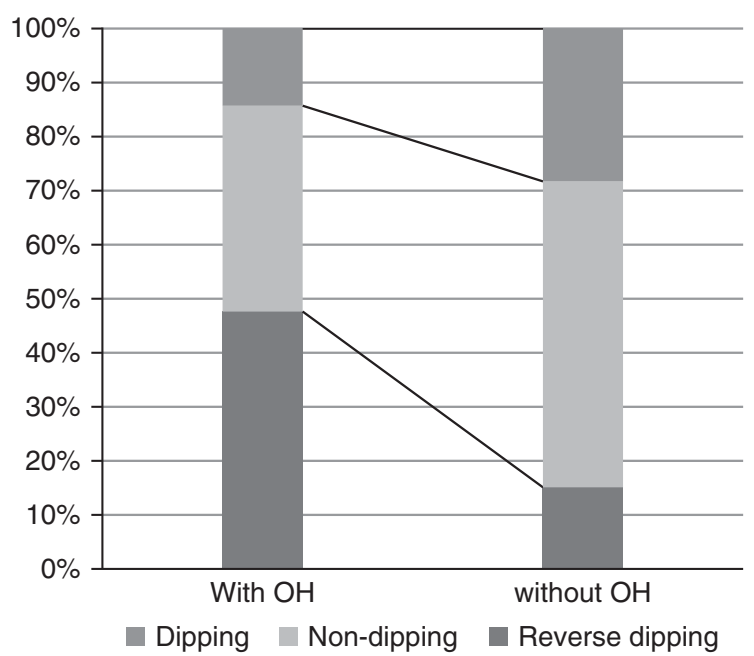

Figure 2: 24-hour blood pressure circadian patterns in with and without orthostatic hypotension. $\mathrm{OH}=$ orthostatic hypotension. $p<0.05$. 


\section{Table 4 : Comparisons between patients with and without orthostatic hypotension}

\begin{tabular}{|c|c|c|c|}
\hline & With $\mathrm{OH}(\mathrm{n}=21)$ & Without OH $(n=53)$ & p value* \\
\hline Sex: female/male & $9 / 12$ & $20 / 33$ & $0.686^{\mathrm{b}}$ \\
\hline Age & $68.1 \pm 8.9$ & $68.1 \pm 9.0$ & 0.994 \\
\hline Disease duration (months) & $28.7 \pm 33.5$ & $35.3 \pm 38.2$ & 0.495 \\
\hline Hoehn and Yahr staging & $2.3 \pm 1.2$ & $2.0 \pm 0.7$ & 0.336 \\
\hline UPDRS part III & $29.1 \pm 18.7$ & $23.9 \pm 13.7$ & 0.191 \\
\hline Diagnosis (SWEDDs/PD) & $4 / 17$ & $24 / 29$ & $0.037 \dagger$ \\
\hline \multicolumn{4}{|l|}{ 24-h ABPM } \\
\hline Daytime mean SBP $(\mathrm{mmHg})$ & $122.8 \pm 12.2$ & $127.7 \pm 12.3$ & 0.128 \\
\hline Daytime mean DBP (mmHg) & $76.5 \pm 7.2$ & $76.9 \pm 7.6$ & 0.845 \\
\hline Daytime MABP (mmHg) & $91.9 \pm 8.2$ & $93.8 \pm 8.5$ & 0.392 \\
\hline Daytime mean HR (n/min) & $72.9 \pm 8.0$ & $75.4 \pm 9.1$ & 0.283 \\
\hline Nocturnal mean SBP $(\mathrm{mmHg})$ & $123.8 \pm 18.6$ & $120.3 \pm 16.6$ & 0.426 \\
\hline Nocturnal mean DBP $(\mathrm{mmHg})$ & $75.4 \pm 13.2$ & $72.0 \pm 9.5$ & 0.223 \\
\hline Nocturnal MABP $(\mathrm{mmHg})$ & $91.5 \pm 14.4$ & $88.1 \pm 11.2$ & 0.277 \\
\hline Nocturnal mean HR (n/min) & $64.2 \pm 9.1$ & $67.5 \pm 9.9$ & 0.200 \\
\hline 24-h mean SBP (mmHg) & $123.0 \pm 13.1$ & $125.4 \pm 12.9$ & 0.468 \\
\hline 24-h mean DBP (mmHg) & $76.0 \pm 8.6$ & $76.6 \pm 9.3$ & 0.774 \\
\hline 24-h MABP (mmHg) & $91.6 \pm 9.5$ & $92.9 \pm 9.5$ & 0.607 \\
\hline 24-h mean HR $(\mathrm{n} / \mathrm{min})$ & $70.8 \pm 8.1$ & $73.7 \pm 10.6$ & 0.260 \\
\hline Diurnal hypertension, $\mathrm{n}(\%)$ & $0(0 \%)$ & $9(17 \%)$ & $0.045 \dagger$ \\
\hline Nocturnal hypertension, n (\%) & $13(61.9 \%)$ & $28(52.8 \%)$ & $0.482 \dagger$ \\
\hline Nocturnal BP dip (\%) & $-0.7 \pm 10.3$ & $5.9 \pm 7.8$ & $0.002 \dagger$ \\
\hline Nocturnal BP pattern & & & $0.010 \dagger$ \\
\hline Dipping, n (\%) & $3(14.3 \%)$ & $15(28.3 \%)$ & \\
\hline Nondipping, n (\%) & $8(38.1 \%)$ & $30(56.6 \%)$ & \\
\hline Reverse dipping, n (\%) & $10(47.6 \%)$ & $8(15.1 \%)$ & \\
\hline Nocturnal pulse decrease & $8.66 \pm 5.68$ & $7.9 \pm 9.9$ & 0.768 \\
\hline \multicolumn{4}{|l|}{ MIBG uptake } \\
\hline Early & $1.9 \pm 0.5$ & $2.3 \pm 0.5$ & 0.019 \\
\hline Late & $1.9 \pm 0.6$ & $2.4 \pm 0.8$ & 0.020 \\
\hline Washout & $22.6 \pm 11.7$ & $19.2 \pm 12.3$ & 0.287 \\
\hline
\end{tabular}

*Student $t$ test.

$\dagger$ Pearson $\chi^{2}$ test.

baroreflex failure. $^{21}$ Nondipping accompanied by nocturnal hypertension shared a common mechanism with orthostatic hypotension in PD. Autonomic dysfunction in PD has been investigated by various methodologies. Autonomic dysfunction, at least as reflected by sympathetic noradrenergic denervation, seems to occur independently of the dopaminergic lesion that produces the movement disorder in PD. ${ }^{22}$ Therefore, nondipping and nocturnal hypertension can be observed in SWEDDs patients independently of the dopaminergic deficits. ${ }^{23}$ However, there are significant differences in MIBG uptake between SWEDDs and PD patients that contribute to the former's lack of postganglionic cardiac sympathetic denervation. Therefore, other types of autonomic dysfunction may contribute to the nondipping in SWEDDs patients. Alternatively, SWEDDs patients could have a form of PD without evidence of postganglionic cardiac sympathetic denervation.
There have been few studies of the possible correlation between MIBG uptake and systemic BP profiles. ${ }^{8,12}$ MIBG uptake has been reported to be correlated with nocturnal BP dips $;{ }^{12}$ however, we could not found any correlation between MIBG uptake and systemic BP profiles in each groups. Interestingly, the nondipping patterns in the two groups (PD and SWEDDs patients) were similar. However, they differed with respect to the early and delayed $\mathrm{H} / \mathrm{M}$ ratio on the MIBG scan. The SWEDDs group had nearly normal MIBG uptake, whereas the PD group had decreased MIBG uptake. This finding implies that the mechanism of nondipping in SWEDDs patients is different from that in PD. We also do not know about the mechanism of this nondipping, as other mechanisms would exist in SWEDDs.

In addition, there have been few studies of the correlation between orthostatic hypotension and autonomic dysfunction 
Table 5: ${ }^{123}$ I-FP-CIT PET/CT results

\begin{tabular}{|c|c|c|c|c|}
\hline & SWEDDs $(n=28)$ & PD $(n=46)$ & p value & Control $(n=26)(16)$ \\
\hline Age & $70.0 \pm 8.4$ & $66.9 \pm 9.1$ & $<0.001$ & $61.88 \pm 1.88$ \\
\hline Left caudate & $3.34 \pm 0.80$ & $2.46 \pm 0.90$ & $<0.001$ & $3.47 \pm 0.38$ \\
\hline Left putamen & $3.43 \pm 0.88$ & $1.58 \pm 0.77$ & $<0.001$ & $3.69 \pm 0.40$ \\
\hline Right caudate & $3.26 \pm 0.79$ & $2.42 \pm 0.89$ & $<0.001$ & $3.52 \pm 0.65$ \\
\hline Right putamen & $3.33 \pm 0.92$ & $1.39 \pm 0.70$ & $<0.001$ & $3.77 \pm 0.38$ \\
\hline Asymmetric index, caudate & $0.05 \pm 0.11$ & $0.11 \pm 0.09$ & 0.003 & $0.04 \pm 0.03$ \\
\hline Asymmetric index, putamen & $0.05 \pm 0.04$ & $0.24 \pm 0.16$ & $<0.001$ & $0.05 \pm 0.03$ \\
\hline
\end{tabular}

Data are mean \pm standard deviation.

(nocturnal BP dip, cardiac MIBG uptake). ${ }^{8,23,24}$ In our study, we divided the SWEDDs and PD patients into two groups based on the presence of orthostatic hypotension and found a significant correlation between orthostatic hypotension/nocturnal BP pattern and cardiac MIBG uptake. This findings may be accounted for by the fact that orthostatic hypotension is a symptom of sympathetic nervous disturbance. In patients with PD and autonomic failure, orthostatic hypotension in the morning hours is caused by natriuresis and polyuria caused by nocturnal hypertension. ${ }^{24,25}$ But not all the patients with orthostatic hypotension in our study had nocturnal hypertension. There is one report that cardiac and vasomotor sympathetic activities are present in early stage de novo PD, even without orthostatic hypotension. ${ }^{26}$ This result could support our observation of nondipping and reverse dipping patterns in the absence of orthostatic hypotension. Conversely, SWEDDs patients may have abnormal vasomotor sympathetic activities. More studies are needed to clarify this matter. In addition, final diagnosis in patients with SWEDDs involving this study had not defined, which is a limitation of our study. We will continue follow-up studies with these subjects.

In this study, we examined the similarities and differences in cardiac autonomic dysfunction between SWEDDs and PD patients. We confirmed that cardiovascular dysautonomia can exist in SWEDDs patients. Furthermore, we concluded that 24-hour ABPM monitoring could be a useful method for detecting cardiovascular dysautonomia in SWEDDs patients.

\section{DisClosures}

None of the authors have anything to disclose.

\section{REFERENCES}

1. Utiumi MA, Felicio AC, Borges CR, Braatz VL, Rezende SA, Munhoz RP, et al. Dopamine transporter imaging in clinically unclear cases of parkinsonism and the importance of scans without evidence of dopaminergic deficit (SWEDDs). Arq Neuropsiquiatr. 2012;70:667-73.

2. Schwingenschuh P, Ruge D, Edwards MJ, Terranova C, Katschnig P, Carrillo F, et al. Distinguishing SWEDDs patients with asymmetric resting tremor from Parkinson's disease: a clinical and electrophysiological study. Mov Disord. 2010;25:560-9.

3. Menendez-Gonzalez M, Tavares F, Zeidan N, Salas-Pacheco JM, Arias-Carrion O. Diagnoses behind patients with hard-to-classify tremor and normal DaT-SPECT: a clinical follow up study. Front Aging Neurosci. 2014;6:56.

4. Marek K, Seibyl J, Eberly S, Oakes D, Shoulson I, Lang AE, et al. Longitudinal follow-up of SWEDD subjects in the PRECEPT Study. Neurology. 2014;82:1791-7.
5. Sommer S, Aral-Becher B, Jost W. Nondipping in Parkinson's disease. Parkinsons Dis. 2011;2011:897586.

6. Moore DJ, West AB, Dawson VL, Dawson TM. Molecular pathophysiology of Parkinson's disease. Annu Rev Neurosci. 2005;28:57-87.

7. Sung VW, Nicholas AP. Nonmotor symptoms in Parkinson's disease: expanding the view of Parkinson's disease beyond a pure motor, pure dopaminergic problem. Neurol Clin. 2013;31(3 Suppl):S1-16.

8. Berganzo K, Diez-Arrola B, Tijero B, Lezcano E, Llorens V, Ugarriza I, et al. Nocturnal hypertension and dysautonomia in patients with Parkinson's disease: are they related? J Neurol. 2013;260:1752-6.

9. Oh YS, Kim JS, Yang DW, Koo JS, Kim YI, Jung HO, et al. Nighttime blood pressure and white matter hyperintensities in patients with Parkinson disease. Chronobiol Int. 2013;30:811-7.

10. Schmidt C, Berg D, Herting, Prieur S, Junghanns S, Schweitzer K, et al. Loss of nocturnal blood pressure fall in various extrapyramidal syndromes. Mov Disord. 2009;24:2136-42.

11. Kwon HM, Lim JS, Kim YS, Moon J, Park H, Kim HY, et al. Cerebral microbleeds are associated with nocturnal reverse dipping in hypertensive patients with ischemic stroke. BMC Neurol. 2014;14:8.

12. Manabe Y, Fujii D, Kono S, Sakai Y, Tanaka T, Narai H, et al. Systemic blood pressure profile correlates with cardiac 123I-MIBG uptake in patients with Parkinson's disease. J Neurol Sci. 2011;307:153-6.

13. Hughes AJ, Daniel SE, Kilford L, Lees AJ. Accuracy of clinicaldiagnosis of idiopathic Parkinsons disease - a clinicopathological study of 100 cases. J Neurol Neurosur Psychiatry. 1992;55:181-4.

14. Freeman R, Wieling W, Axelrod FB, Benditt DG, Benarroch E, Biaggioni I, et al. Consensus statement on the definition of orthostatic hypotension, neurally mediated syncope and the postural tachycardia syndrome. Auton Neurosci. 2011;161:46-8.

15. Pickering TG, Hall JE, Appel LJ, Falkner BE, Graves J, Hill MN, et al. Recommendations for blood pressure measurement in humans and experimental animals: part 1: blood pressure measurement in humans: a statement for professionals from the Subcommittee of Professional and Public Education of the American Heart Association Council on High Blood Pressure Research. Circulation. 2005;111:697-716.

16. Jang W, Kim JS, Cho JW, Kim YH, Kim JY, Choi YY, et al. Cardiac sympathetic denervation in Parkinson's disease patients with SWEDDs. Neurol Sci. 2013;34:1375-82.

17. Silveira-Moriyama L, Schwingenschuh P, O'Donnell A, Schneider SA, Mir P, Carrillo F, et al. Olfaction in patients with suspected parkinsonism and scans without evidence of dopaminergic deficit (SWEDDs). J Neurol Neurosurgery Psychiatry. 2009;80:744-8.

18. Kim JE, Shin JS, Jeong JH, Choi KG, Park KD, Kim S. Relationships between 24-hour blood pressures, subcortical ischemic lesions, and cognitive impairment. J Clin Neurol. 2009;5:139-45.

19. Birkenhager AM, van den Meiracker AH. Causes and consequences of a non-dipping blood pressure profile. Neth J Med. 2007;65: 127-31.

20. Kanbay M, Turgut F, Uyar ME, Akcay A, Covic A. Causes and mechanisms of nondipping hypertension. Clin Exp Hypertens. 2008;30:585-97. 
21. Jain S, Goldstein DS. Cardiovascular dysautonomia in Parkinson disease: from pathophysiology to pathogenesis. Neurobiol Dis. 2012;46:572-80.

22. Goldstein DS, Sewell L, Sharabi Y. Autonomic dysfunction in PD: a window to early detection? J Neurol Sciences. 2011; 310:118-22.

23. Oh YS, Kim JS, Chung YA, You IeR, Yang DW, Chung SW, et al. Orthostatic hypotension, non-dipping and striatal dopamine in Parkinson disease. Neurol Sci. 2013;34:557-60.
24. Matsui H, Nishinaka K, Oda M, Komatsu K, Kubori T, Udaka F. Does cardiac metaiodobenzylguanidine (MIBG) uptake in Parkinson's disease correlate with major autonomic symptoms? Parkinsonism Related Disord. 2006;12:284-8.

25. Wilcox CS, Aminoff MJ, Slater JD. Sodium homeostasis in patients with autonomic failure. Clin Sci Mol Med. 1977;53:321-8.

26. Oka H, Mochio S, Onouchi K, Morita M, Yoshioka M, Inoue K. Cardiovascular dysautonomia in de novo Parkinson's disease. J Neurol Sci. 2006;241:59-65. 